\title{
Spectroscopic analysis on Synthesis 1-Methyl-3-(2'-Phenylethyl)- 1H,3H-Quinazoline-2,4-dione
}

\author{
Sushika Joshi (Mulmi) \\ Central Department of Chemistry, Tribhuvan University, Kirtipur, Kathmandu, Nepal
}

\begin{abstract}
Carbomethoxy-methylanthranilic acid was synthesized from methylanthranilic acid with methylchloroformate in presence of potassium carbonate. Cyclisationreaction of $N$ carbomethoxymethylanthranilic acid was performed by heating to get N-methylisatoic anhydride. 2metholamino-N-(2'-phenylethyl) benzamidewas formed from Isatoic anhydride and phenylethyl amine. High yield of 1-methyl-3-(2'- phenylethyl)-1H,3H-quinazoline-2,4-dione alkaloids were formed by condensation and cyclisation reaction between amide and methylchloroformate. The synthesis compound was identified with the help of its melting point, $C^{13} N M R$ and $H^{l} N M R$ spectra.
\end{abstract}

KEYWORD: $C^{13} N M R, H^{l} N M R$, Carbomethoxy-methylanthranilic acid,quinazoline, alkaloid

\section{INTRODUCTION}

Synthetic and natural quinazoline alkaloids are known to have a variety of biological responses. Fifty quinazoline derivatives with varieties of biological activities are used for clinical purposed. Leaves and root of AdhatodavasicaNees, which contain some quinazolines alkaloids, are used for treatments for bronchitis, asthma, diarrhea and dysentery. These parts are also used for antiseptic, antiperiodic and anthelminthic properties [1]. Various types of quinazolinealkaloids and their chemotaxonic efforts are reported in the Rutaceae family. 4quinazolines alkaloids have been isolated from seeds husks of Zanthoxylumarborescens [2]. Anti-Inflammatory activity has been reported in various quinazolines. Substituted at position-3 of the quinazolines nucleus have marked influenced on the activity [3]. In the present work quinazoline alkaloids are synthesized and evaluated their spectroscopy analysis.

\section{METHODOLOGY}

Formation of N-Carbomethoxy-methylanthranilic acid[4]

About $1.51 \mathrm{~g}$ of $\mathrm{N}$-methylanthranilic acid and $0.70 \mathrm{~g}$ ofPotassium carbonate were dissolved in water. After addition of 4-5 ml methylchloroformate, the mixture was shook vigorously and warmed up to $90^{\circ} \mathrm{c}$. Then oil was separated out and white crystal was formed after cooling. The product was recrystallised with hot water. Its Melting point was $137^{\circ} \mathrm{C}$ and the yield was $75.4 \%$.

\section{Formation of $\mathrm{N}$-methylisatoic anhydride[4]}

$1.5 \mathrm{~g}$ of $\mathrm{N}$-methyl Carbomethoxyanthranilic acid was heated up to $220^{\circ} \mathrm{C}$ for half an hour inside the oven. Then after cooling this reddish oil liquid was converted into crystals which were recrystallised with ethanol. The yellow small needle type crystals having melting point of $177^{\circ} \mathrm{C}$ and the yield was $52 \%$.

\section{Formation of 2-metholamino-N-(2'-phenylethyl) benzamide[2]}

About $0.689 \mathrm{~g}$ of isatoic anhydride was dissolved in $0.522 \mathrm{ml}$ of phenylethylamine and then $10 \mathrm{ml}$ of dioxin was added to it. The mixture was heated up to $100^{\circ} \mathrm{C}$ for $10 \mathrm{~min}$. Then excessive amount of water was added to get oil which was crystallized by scratching and cooling. The crystals were washed with $5 \% \mathrm{~K}_{2} \mathrm{CO}_{3}$ and water, and then recrystallised with methanol. Its melting point was $106^{\circ}$ Candthe yield was $70 \%$.

Formation of 1-methyl-3 (2'-phenylethyl)-1H,3H-quinazoline-2,4-dione[2]

The amide was dissolved in dioxin and aqueous solution of $\mathrm{Na}_{2} \mathrm{CO}_{3}$ and then methylchloformate were added to it. The solution was stirred at room temperature for 20 minutes. Excessive amount of water were added then white crystals were appeared. The crystals were washed with dilute $\mathrm{HCl}$ and $5 \% \mathrm{Na}_{2} \mathrm{CO}_{3}$ and recrystallised with $\mathrm{MeOH}$. Its melting point was $101^{\circ} \mathrm{C}$ and yield $88 \%$.

\section{NMR spectroscopy investigation of Quinazoline}

Spectra were recorded on a Brucker DPX 300 FT spectrometer, operating at 293k. Data sets were processed using standard Bruker software.

$\mathrm{H}^{1}: 300,13 \mathrm{MHz}$, internal standard TMS (tetramethylsilane).

$\mathrm{C}^{13}$ : calibrated to $\mathrm{CDCl} 3$ triplett, $(\mathrm{p}=77,0 \mathrm{ppm})$.

Melting points

Melting points was performed on electronic melting point apparatus. 


\section{RESULTS AND DISCUSSION}

N-Carbomethoxy-methylanthranilic acid was sky blue colour with single spot on TLC in $254 \mathrm{~nm}$ ultraviolet light and Rf value was 0.32 on $10 \%$ methanol in chloroform. Formation of N-methylisatoic anhydride was performed by a cyclisation reaction of $\mathrm{N}$-carbomethoxymethylanthranilic acid by heating. It was blue fluorescence in $366 \mathrm{~nm}$ ultraviolet light and $\mathrm{Rf}$ value was 0.79 on mobile phase of $10 \%$ methanol in chloroform. The crystals of amide had melting point sharply $106^{\circ} \mathrm{C}$ and had sky blue fluorescence $366 \mathrm{~nm}$ of ultraviolet light. Condensation and cyclisation reactions were occurred between amide and methylchloroformate, and gave 1methyl-3-(2'- phenylethyl)-1H,3H-quinazoline-2,4-dione alkaloids was formed. It has dark blue fluorescence on $254 \mathrm{~nm}$ ultraviolet light and Rf value was 0.60 on mobile phase of $10 \%$ methanol inchloroform. The yield was $88 \%$. The synthetic route to 1-methyl-3-(2'- phenylethyl)-1H,3H-quinazoline-2,4-dione is shown in figure 1.<smiles>CNc1ccccc1C(=O)O</smiles><smiles>COC(=O)N(C)c1ccccc1C(=O)O</smiles>

N-Carbomethoxy-methyl anthranilic acid

N-Methylanthranilic acid

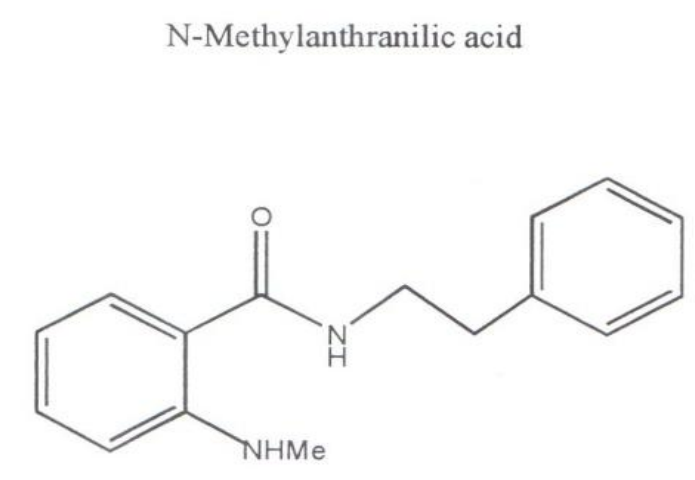

2-Methylamino-N-(2'-phenylethyl) benzamide<smiles>Cn1c(=O)oc(=O)c2ccccc21</smiles>

Isatoicanhydride

$+\mathrm{CO}_{2}$<smiles>CC(=O)N(C)c1ccccc1C(=O)NCCc1ccccc1</smiles>

N-carboxymethoxy methyl-N-( $2^{\prime}$-phenylethyl) benzamide (Intermediate) 


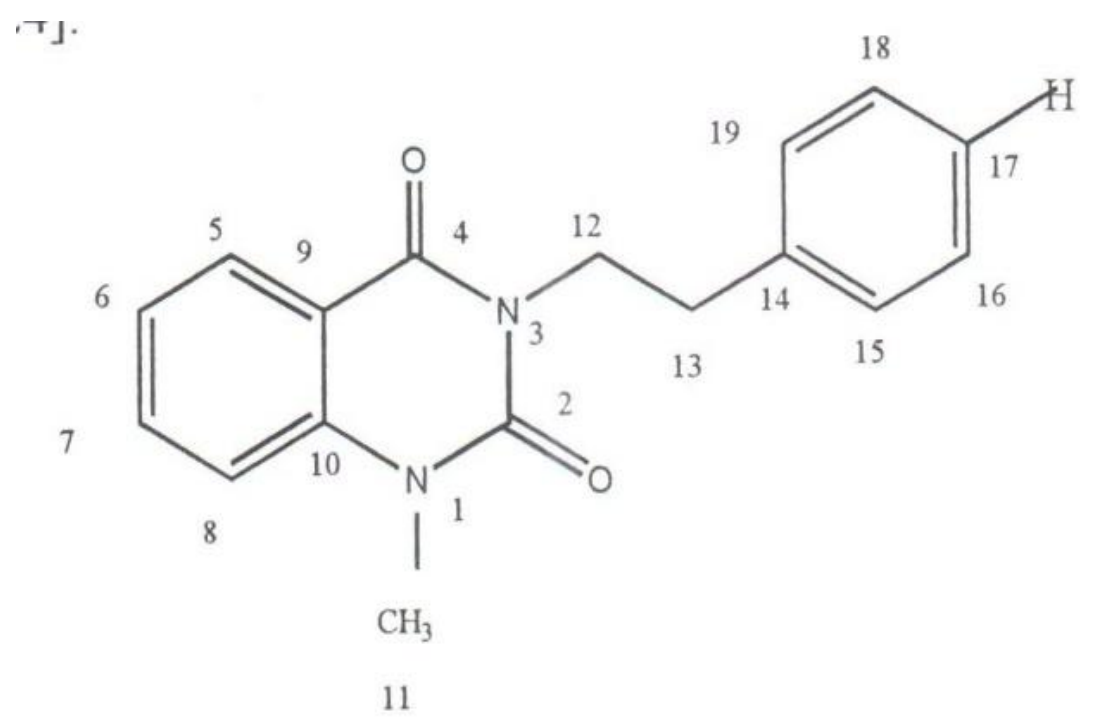

Fig. 1: synthetic route to 1-methyl-3-(2'- phenylethyl)-1H,3H-quinazoline-2,4-dione

\section{NMR spectroscopy investigation of Quinazoline alkaloids.}

The obtained experimental data of ${ }^{1} \mathrm{H}-\mathrm{NMR}$ spectrum are as follows: ${ }^{1} \mathrm{H}-\mathrm{NMR}\left(\mathrm{CDCl}_{3}\right): 8.36-8.33(\mathrm{~m}$, 1H,h-5), 7.79-7.77( $m, 1 \mathrm{H}, \mathrm{H}-8), 7.47-7.30(m, 7 \mathrm{H}, \mathrm{H}-15, \mathrm{H}-16, \mathrm{H}-17 . \mathrm{H}-18, \mathrm{H}-19, \mathrm{H}-6, \mathrm{H}-7), 4.46-4.39(m, 2 \mathrm{H},-\mathrm{N}-$ $\left.\mathrm{CH}_{2}-\right), 3.72\left(\mathrm{~m}, 3 \mathrm{H}, \mathrm{N}-\mathrm{CH}_{3}\right)$ and 3.12-3.07 $\left(m, 2 \mathrm{H}, \mathrm{Ar}-\mathrm{CH}_{3}\right)$. The spectrum of fig 2 shows two multipletes of 3.10 and 4.32ppm, representing the ethylene group of the side chain. The $\mathrm{N}$-methyl group could be found at $3.72 \mathrm{ppm}$. The results are total agreement with published data $\{2\}$.

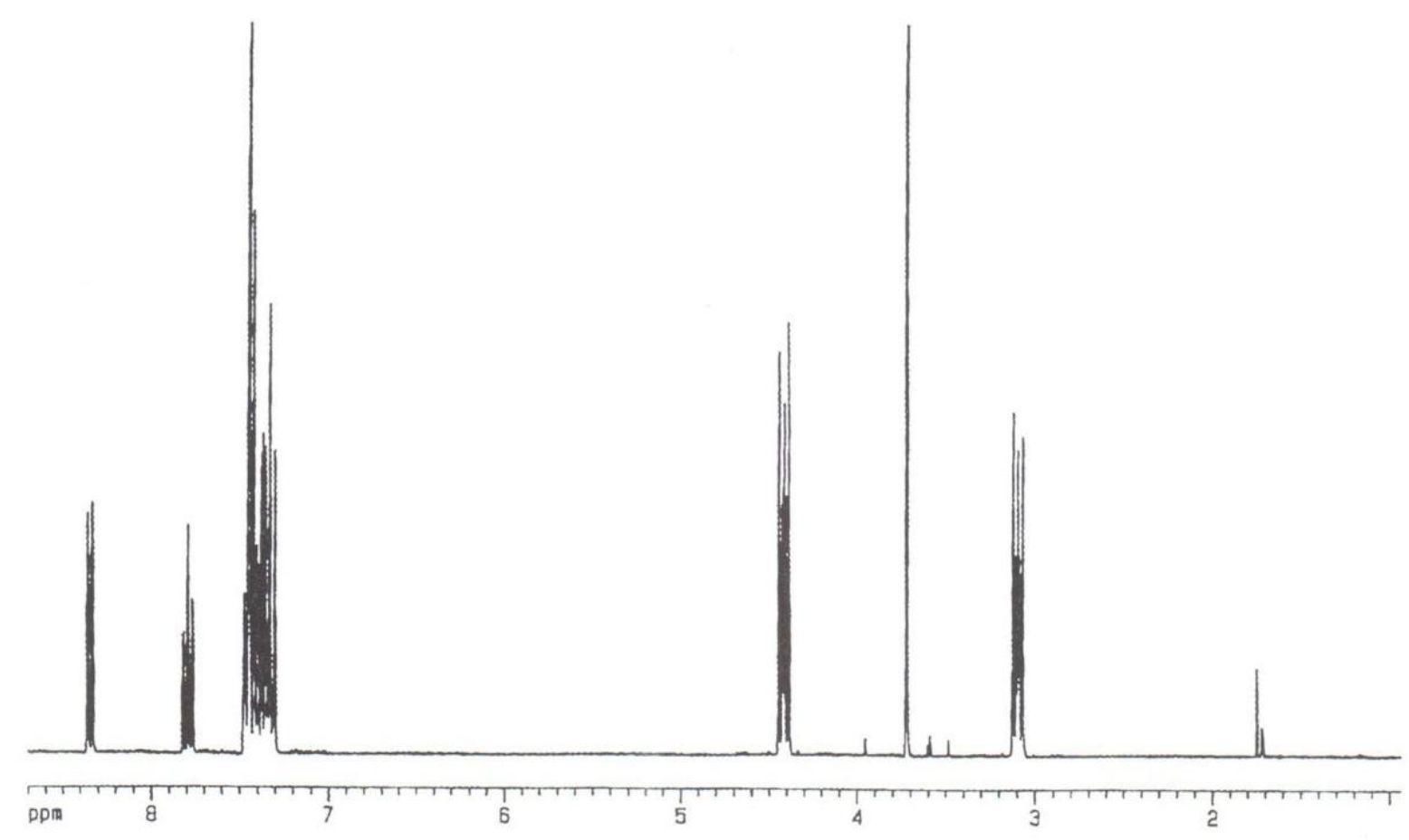

Fig. 2: ${ }^{1}$ HNMR spectrum of Quinazoline alkaloids. 


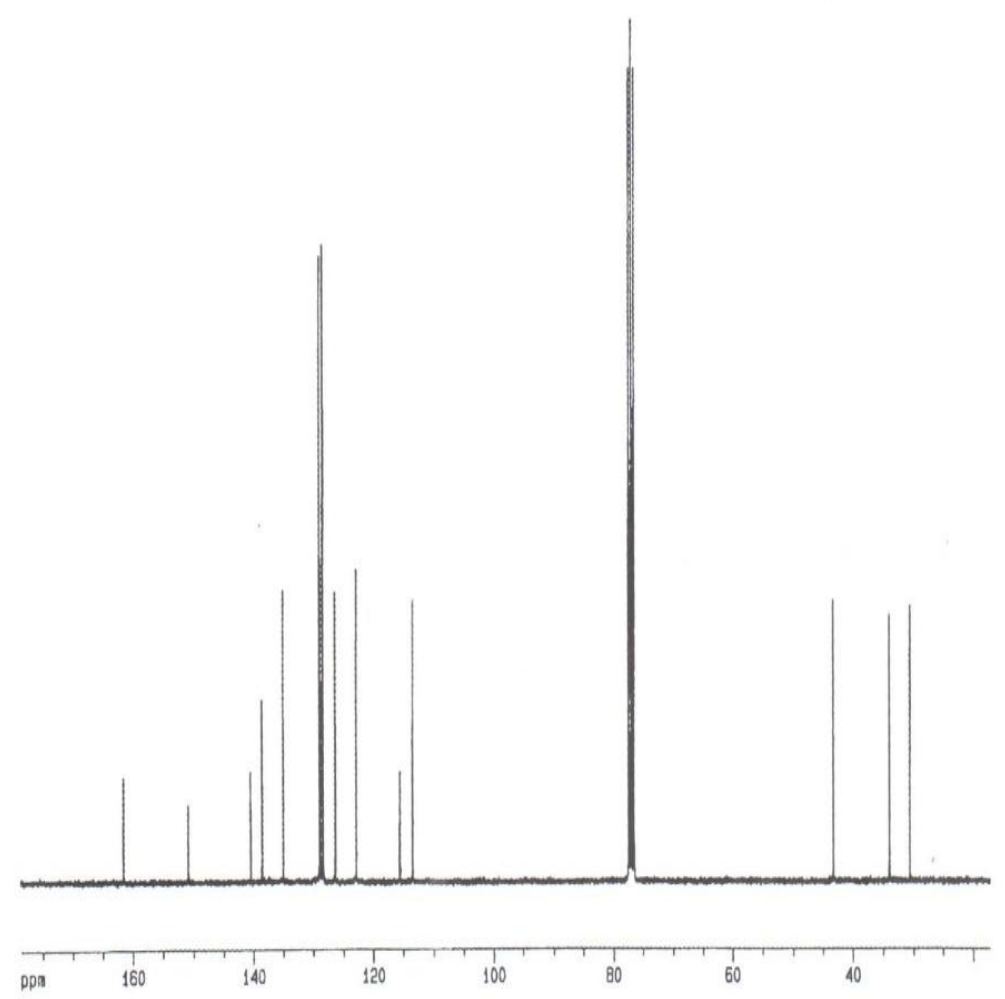

Fig. 3: ${ }^{13} \mathrm{C}-\mathrm{NMR}$ spectrum of Quinaziline alkaloids.

The obtained experimental data of ${ }^{13} \mathrm{C}-\mathrm{NMR}$ spectrum are as follows:- ${ }^{13} \mathrm{C}-\mathrm{NMR}\left(\mathrm{CDCl}_{3}\right)$ : $161.57(\mathrm{C}-$ 4), 150.85 (C-10), 140.49 (C-2), 138.61 (C-14), 135.03 (C-7), 128.97 (C-15 and 19).128.87 (C-5), 128.46 (C16 and 18), 126.42 (C-17), 122.92 (C-6), 115.57 (C-9), 113.47 (C-8), 43.30 (C-13), 34.01 (c-12) and 30.64 (C-11). The results obtained from ${ }^{13} \mathrm{C}-\mathrm{NMR}$ spectrum in figure 3 are total agreement with the published data $\{2\}$.

\section{CONCLUSION}

Spectroscopic analysis method was used to identify the product. The synthesis process is a useful method for the preparation of quinazoline alkaloids with highly yield as well as easily accessible starting materials.

\section{ACKNOWLEDGMENTS}

The author would like to express hersincere gratitude to thesupervisor Professor Dr. Robert Ebermann of University of Bodenkultur, Wien, Austria for his invaluable guidance, support and lab facilities provided for this research work.

\section{REFERENCES}

[1] Fujita E., Johne S., Kasai R., Node M., Tanaka O. (1984), Biological Activity of natural and SyntheticQuinalones, Progress in the chemistry of organic natural (46), 221-219.

[2] David L Dreyer and R. C.Brenner (1980), Alkaloids of some Mexican ZanthoxylumSpecies, Phytochemistry, vol 19, pp 935-939.

[3] Saxena S., M. Verma, A. K. Saxena and K. Shanker (1991), Anti-Inflammatory quinazolinonesIndian J. Pharma. Sci., 1991 (53) (2),48-52.

[4] Berichte der DeutschenChemisishenGesellshaft, Jahrg, XXXXII, pp. 3193. 